Int. J. Dev. Biol. 58: 575-583 (2014)

doi: $10.1387 / \mathrm{ijdb} .140100 \mathrm{ca}$

\title{
Development of a feeding trochophore in the polychaete Hydroides elegans
}

\author{
CESAR ARENAS-MENA*,1 and AVA LI ${ }^{2}$ \\ ${ }^{1}$ Department of Biology, College of Staten Island and Graduate Center, The City University of New York (CUNY), NY and \\ ${ }^{2}$ Broad Institute of MIT, MA, USA
}

\begin{abstract}
Hydroides elegans is an indirectly developing polychaete with equal spiral cleavage, gastrulation by invagination, and a feeding trochophore. Expression of several transcription factors and differentiation genes has been characterized. Comparative analysis reveals evolutionarily conserved roles. For example, the synexpression of transcription factors FoxA and Brachyury suggests homology of primary and secondary gut openings in protostomes and deuterostomes, and the expression of Sall suggests similar regulatory controls in the posterior growth zone of bilaterians. Differences in gene expression suggest regulatory differences control gastrulation by invagination in polychaetes with a feeding trochophore and gastrulation by epiboly in polychaetes without a feeding trochophore. Association of histone variant H2A.Z with transcriptional potency and its expression suggest a developmental role during both embryogenesis and the larva-to-adult transformation. Methods are being developed for experimental exploration of the gene regulatory networks involved in trochophore development in Hydroides. It is unknown if polychaete feeding trochophores evolved from a larval stage already present in the life cycle of the last common ancestor of protostomes and deuterostomes. Previous evolutionary scenarios about larval origins overemphasize the discontinuity between larval and adult development and require the early evolution of undifferentiated and transcriptionally potent "set aside" cells. Indirect development may proceed by developmental remodeling of differentiated cells and could have evolved after gradual transformation of juveniles into larvae; undifferentiated and transcriptionally potent cells would have evolved secondarily. Comprehensive characterization of gene regulatory networks for feeding trochophore development may help resolve these major evolutionary questions.
\end{abstract}

KEY WORDS: bilaterian, posterior growth, serpulid, annelid

\section{Hydroides elegans, a polychaete with a feeding trochophore}

Characterization of polychaetes with a feeding trochophore, such as Hydroides elegans (Fig. 1 and Table 1), is relevant to understand the developmental evolution of complex life cycles in spiralians. Embryonic development in polychaetes conforms to the presence or absence of a feeding trochophore (Fig. 2). In the genus Hydroides (Eupomatus), embryogenesis ends in a feeding trochophore endowed with an equatorial ciliary band, a protonephridium, various sensory organs, and a functional gut formed after gastrulation by invagination (Hatschek, 1885; Shearer, 1911). Blastomeres $4 d$ and $2 d 22$ are inconspicuous and fated to contribute to the mesodermal and ectodermal portions of the segmented body that will have primarily a reproductive role; the growth and proliferation of $4 \mathrm{~d}$ and $2 \mathrm{~d} 22$ are feeding-dependent. In contrast, during embryogenesis in polychaetes without feeding larvae, blastomeres $4 \mathrm{~d}$ and $2 \mathrm{~d}$ are relatively large and immediately engage in the formation of segments (Fig. 2). In addition to large $4 \mathrm{~d}$ and $2 \mathrm{~d} 2$, further nourishment is provided by large and yolky endodermal precursors that are passively internalized during epibolic gastrulation and do not form a functional larval gut (Anderson, 1966). Thus, embryos forming feeding trochophores develop a functional gut immediately, but development of the segmented region is feeding-dependent; whereas embryos giving rise to non-feeding trochophores promptly initiate segment formation but postpone gut formation. Delineating the regulatory mechanisms controlling these significant developmental differ-

Abbreviations used in this paper: PGZ, posterior growth zone.

\footnotetext{
*Address correspondence to: Cesar Arenas-Mena. Department of Biology, College of Staten Island, CUNY. 2800 Victory Boulevard, Staten Island, NY, 10314. E-mail: cesar.arenasmena@csi.cuny.edu
}

Accepted: 20 June 2014.

ISSN: Online 1696-3547, Print 0214-6282 

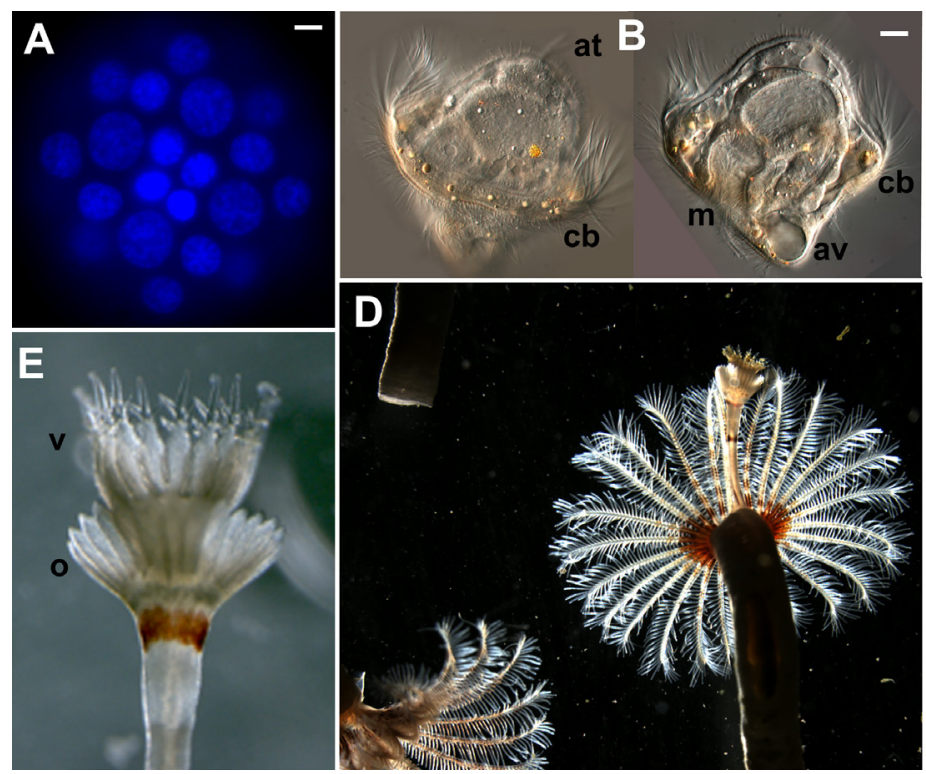

ences could shed light on the ancestral developmental mode in polychaetes, spiralians, protostomes and bilaterians.

\section{Spiral -sinistral- equal cleavage in Hydroides and early gene expression}

Not all polychaetes are unequal cleavers. In polychaetes with a feeding trochophore, blastomeres $\mathrm{A}, \mathrm{B}, \mathrm{C}$ and $\mathrm{D}$ are of equal size (Anderson, 1966). In Hydroides, the D quadrant becomes apparent in the 60-cell embryo after the asymmetric division of $2 \mathrm{~d} 2$ into the large animal-side descendant $2 \mathrm{~d} 21$ and the small vegetal-side sister $2 \mathrm{~d} 22$, whereas the divisions of equivalent blastomeres $2 \mathrm{a} 2,2 \mathrm{~b} 2$ and $2 \mathrm{c} 2$ are indistinguishable among quadrants (Arenas-Mena, 2007b). It remains untested if equal size in Hydroides corresponds with equal developmental potential. Polychaetes lacking larval stages or with non-feeding trochophores develop through unequal cleavage, the $D$ blastomere of the 4-cell embryo being larger than the A, B and $C$ blastomeres (Anderson, 1966). D-quadrant specification in Hydroides involves activation of the MAPK pathway, which is also activated in other equal- and unequal-cleaving spiralians (Lambert and Nagy, 2003). Subsequently, the transcription factor $T b x 2 / 3$ is expressed in dorsal cells of all three germ layers (Arenas-Mena, 2013) in a pattern generally similar to the expression of its sea urchin ortholog, which has a dorsal specification role (Gross, 2003). The conserved expression suggests the possibility of an ancestral role of $T b \times 2 / 3$ in dorsal specification shared by protostomes and deuterostomes (Arenas-Mena, 2013).

In Hydroides elegans the spiral cleavage is sinistral: the third cleavage that initiates the "spiral" phase is tilted in a counterclockwise orientation as seen from the animal pole (Arenas-Mena, 2007b). The distribution of dextral and sinistral cleavage among species in the genus remains uncertain. In the related species Hydroides eupomatus, the cleavage was described as dextral (Hatschek, 1885; Shearer, 1911). In gastropods, dextral and sinistral species have been described (Schilthuizen and Davison, 2005). Some species maintain dimorphism among individuals, although selection generally favors the consolidation of chirality (Utsuno et al., 2011). Cytoskeletal differences implementing alternative chirality within

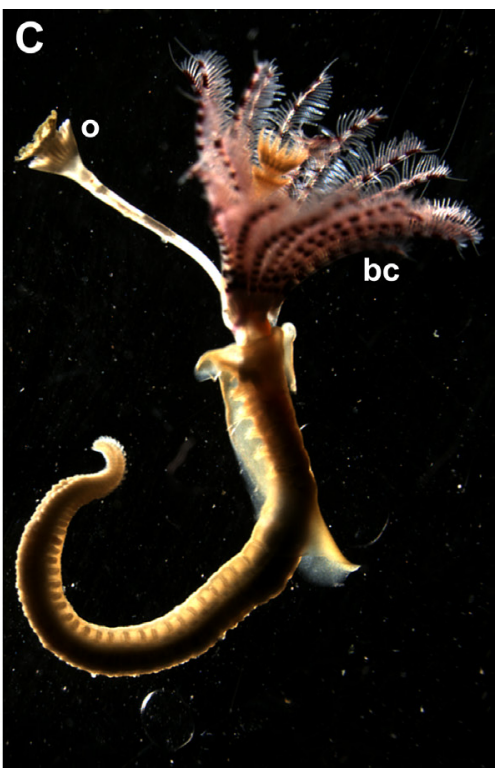

Fig. 1. Hydroides elegans, a serpulid with a feeding trochophore. (A) Animal cap view of a 64-cell embryo, nuclear staining (Arenas-Mena, 2007b). (B) Consecutive optical sections of a 24-hour trochophore larva with differentiated ciliary band, foregut, mouth, midgut, hindgut, apical tuft, eye and anal vesicle (see diagram in figure 2). (C) Adult outside the tube. This individual has two operculums. (D) Adults in their calcareous tubes. At center, with the branchial crown fully extended. At top-left, an individual fully retracted inside the calcareous tube. (E) Detail of the operculum, which can be used for species identification if the spiny verticil is present (Bastida-Zavala and Ten Hove, 2003).

species have been identified in Lymnaea stagnalis (Shibazaki et al., 2004), but the earliest genetic mechanisms that determine spindle orientation among dextral and sinistral species remain unknown. In mollusks, spiral cleavage correlates with shell coiling, but in Hydroides we do not know which left-right asymmetries correlate with spiral handedness, if any. Despite their respective sinistral and dextral patterns, in Hydroides elegans and Hydroides eupomatusthe operculum develops first on the left side, suggesting that left-right asymmetries in the genus are independent of spiralcleavage chirality. Asymmetry in the order of eye formation has been described among serpulid species (Segrove, 1941; Wisely, 1958; Arenas-Mena, 2008), but its correlation with cleavage chirality remains uncertain. It will be interesting to find out how chirality in the genus correlates with the temporal and/or spatial left-right asymmetric expression of transcription factors Blimp, Sall and Tbx2/3 identified during Hydroides elegans development (ArenasMena 2008, 2013).

Asymmetric cell divisions associate with invariant fates. Volumetric analysis has not been performed, but asymmetry is obvious for some cell divisions. For example, $1 \mathrm{q} 111$ is much smaller than 1 q112 (see Fig. 2A, q stands for quadrants a, b, c and d jointly), dorsal blastomeres $2 \mathrm{~d} 22$ and $4 \mathrm{~d}$ are much smaller than sister blastomeres 2d21 and 4D (Fig. 2A). In all cases, invariant fate is observed: blastomeres 1q111 become apical tuft cells (Fig. 2 A), $2 \mathrm{~d} 22$ and $4 \mathrm{~d}$ are ectoderm and mesoderm precursors of the posterior growth zone, respectively (Fig. 2A). Similarly, neighboring sisters 1q22 and 1q21 elegantly divide in complementary asymmetric patterns in each quadrant to invariably position in the same plane the eight primary trochoblasts $1 \mathrm{q} 221$ and $1 \mathrm{q} 212$ that are much larger than their respective vegetal 1q222 and animal 1q211 sisters (Arenas-Mena et al., 2007a). It remains uncertain if cells undergoing symmetric cell divisions similarly correspond to invariant fates, or if more flexibility and/or later specification ensues in these lineages.

Remarkably, all the transcription factors characterized so far initiate their expression in strikingly precise association with the invariant cleavage (Arenas-Mena, 2006, 2008, 2013; Arenas-Mena and Wong 2007). For example, FoxA1 initiates its expression 
early in the four blastomeres $2 q$ of the 16-cell embryo (Fig. 3); Otx initiates its animal expression in the four $1 \mathrm{q} 12$ blastomeres and later its vegetal expression in 2a22, $2 b 22$ and 2c22 (Fig. 3). Initial invariability of gene expression could correspond to mRNA segregation associated with the cleavage machinery, as previously described in the gastropod Ilyanassa obsoleta (Lambert, 2010; Chan and Lambert 2011). For most transcription factors analyzed so far, the invariable initial expression is followed by rapid expression shifts across blastomere lineages; that is, expansion to initially non-expressing blastomeres and/or restriction of expression within a subset of lineage descendants. Expression shifts may correspond to various inductive events among blastomeres and/or to the autonomous dynamics of gene regulatory networks. These dynamic expression patterns seemingly correlate with morphogenetic processes rather than with cell-type differentiation. For example, Brachyuryand Sallinitiate their expression in association
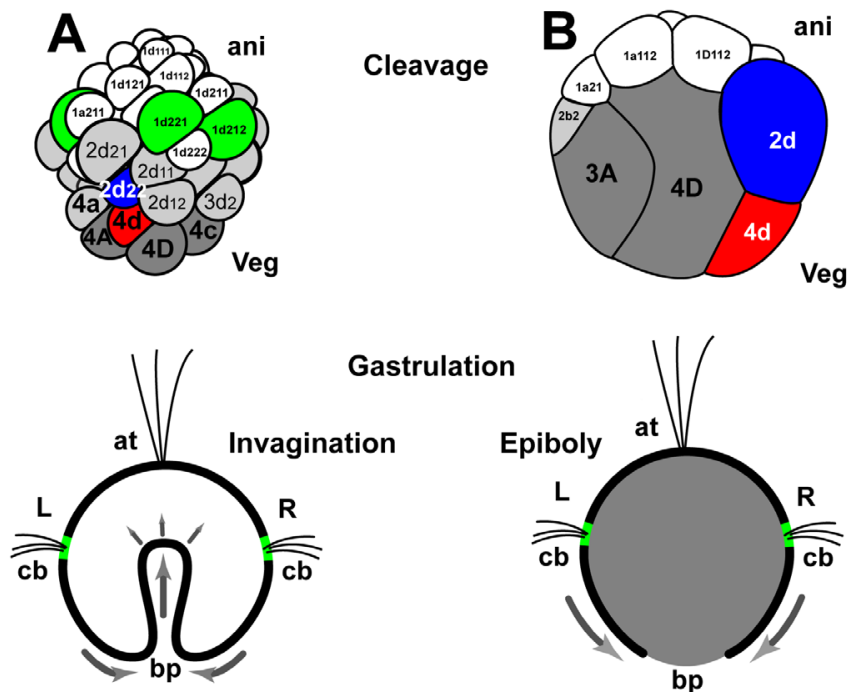

Gastrulation
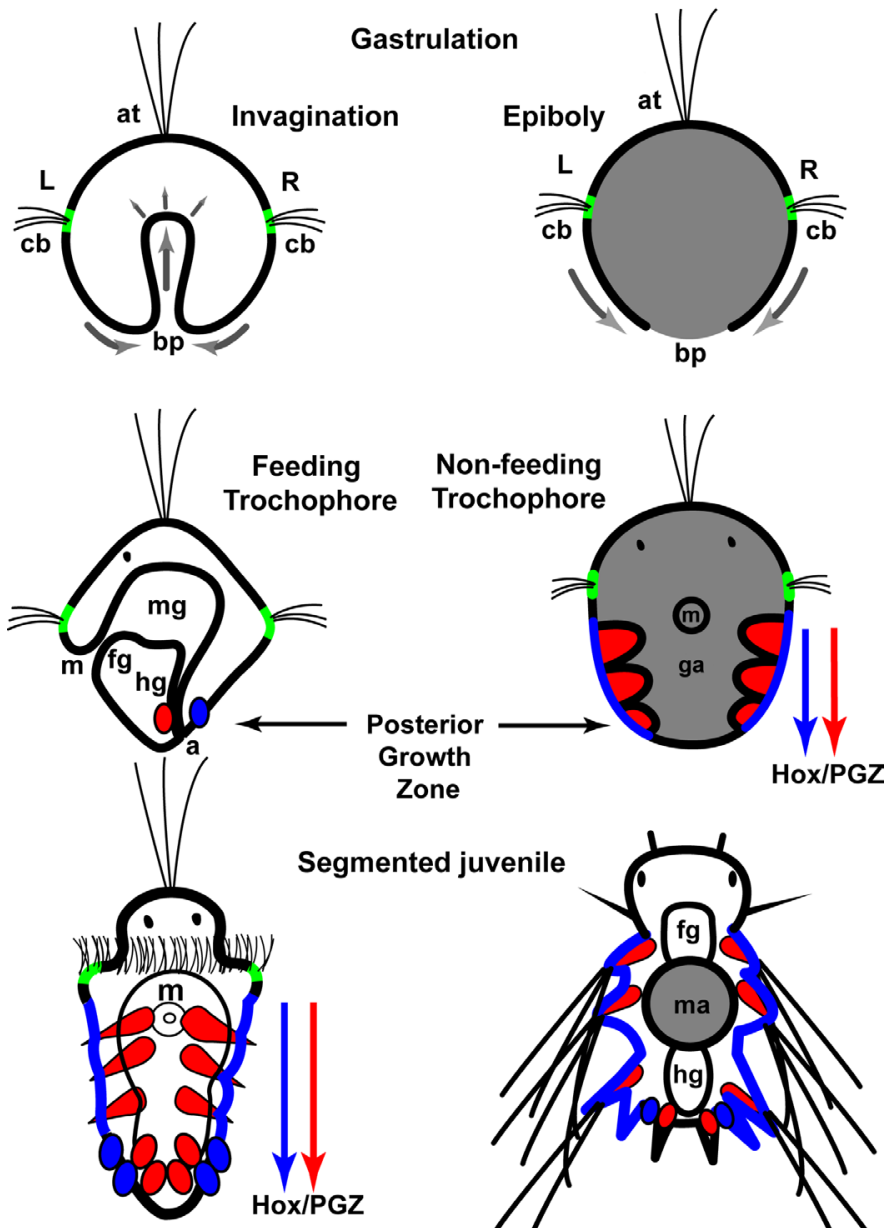

Zone Hox/PGZ

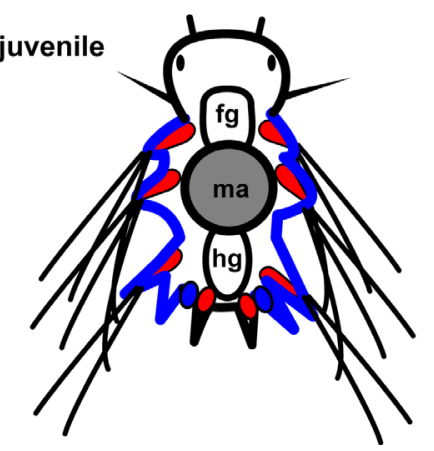

with invariable blastomeres, but their expression shifts in anticipation of gastrulation (Arenas-Mena, 2006, 2013). Lineage-free gene expression could correspond with variability of lineage fate; although, general invariability of lineage fate is expected given that only one more cell division, on average, separates the clearly invariant phase, at least up to 80 cells, from the approximately 160 cells of the feeding trochophore (Arenas-Mena, 2007b). For some genes, invariable gene expression correlates with immediate differentiation, such as the animal cap blastomeres expressing Otx, which apparently differentiate into neurons (Fig. 3) (Arenas-Mena and Wong, 2007), or the restriction of T-brain to apical tuft sensory precursors (Fig. 3) (Arenas-Mena, 2008). In general, transcription factor gene expression declines before differentiation, which prevents its unambiguous correlation with larval fates.

\section{Gene expression during the development of a feeding trochophore}

The embryo and larva of Hydroides can be conveniently subdivided in animal and vegetal hemispheres, corresponding to animal $1 \mathrm{q}$ and vegetal $1 \mathrm{Q}$ blastomere descendants, respectively (ArenasMena, 2007b). The animal cap has ectodermal neural and sensory fates, with a belt of eight primary trochoblasts located just above the equator and a sensory apical tuft by the animal pole (ArenasMena et al., 2007a). The vegetal hemisphere includes ectoderm, endoderm and mesoderm precursors plus the posterior growth zone endomesoderm precursor $4 \mathrm{~d}$ and ectoderm precursor $2 \mathrm{~d} 22$ (Fig. 2). The animal-vegetal compartments are partially blurred by animal cap cells that apparently migrate from the animal to the vegetal hemispheres through a small dorsal gap in the ciliary band (Mead, 1897; Treadwell, 1901; Arenas-Mena and Wong, 2007). Subsequent to spiral cleavage, gastrulation and ectoderm

Fig. 2. Comparison of direct and indirect development in polychaetes. Adapted from Arenas-Mena, 2013. (A) Development of a serpulid with a feeding trochophore. (B) Development of a nereid with a non-feeding trochophore. Embryos in A and B depicted at similar size for clarity; the actual relative size of indirectly developing embryos is much smaller (Anderson, 1966). (1st row) Gray and colors denote vegetal hemisphere blastomeres; animal hemisphere blastomeres are in white. Blastomeres fated to midgut (dark gray), posterior growth zone (PGZ) mesoderm (red) and PGZ ectoderm (blue) are of large size in directly developing nereids, whereas a larger number of blastomeres have larval fates in indirectly developing serpulids. (2nd row) Gastrulation in indirectly developing polychaetes with a feeding trochophore proceeds by active invagination of the endoderm to form the gut epithelium (gastrulation movements indicated by gray arrows). In polychaetes with a non-feeding trochophore the passive and yolky endoderm precursors are internalized by epiboly (the ectoderm actively encloses the passive endoderm). (3rd and 4th rows) The feeding trochophore of a prototypical indirectly developing serpulid has a functional tripartite gut, and precursors of the segmented portion of the worm are inconspicuous (red and blue); only after feeding is the segmented portion formed by posterior growth. The non-feeding trochophore of a prototypic nereid lacks a functional epithelial gut. Its endoderm consists of compact and yolky cells that form the blind gut anlage (ga); posterior growth during non-feeding larval stages starts during embryogenesis. Incipient crawling worms of direct developers still lack feeding capability, and nourishment remains dependent on the yolky midgut anlage (ma). Blastomere designations as previously summarized (Anderson, 1966; Arenas-Mena, 2007b). a, anus; ani, animal; at, apical tuft; bp, blastopore; cb, ciliary band; d, dorsal; fg, foregut; hg, hindgut; $L$, left; $m$, mouth; mg, midgut; 0 , oral; $R$, right; $P G Z$, posterior growth zone; $v$, ventral; Veg, vegetal. 
morphogenetic rearrangements ensue (Fig. 2) (Anderson, 1966).

Embryogenesis generates a functional gut in Hydroides. In contrast, directly developing polychaetes and polychaetes with non-feeding trochophores form larvae with yolky "endoderm" cells, and the functional gut forms much later, during larval stages already undergoing posterior growth and segmentation (Fig. 2) (Anderson, 1966). Transcription factors FoxA, Brachyury, T-brain, Blimp, Otx and Sall are expressed in the vegetal hemisphere in dynamic patterns that correlate with morphogenetic events associated with gastrulation by invagination (Arenas-Mena 2006, 2008, 2013; Arenas-Mena and Wong, 2007). FoxA and Brachyury form a synexpression group associated with gastrulation by invagination in bilaterians and cnidarians, suggesting an ancient role (Fritzenwanker et al., 2004; Scholz and Technau, 2003). In addition to their expression in endoderm and ectoderm precursors that anticipates blastopore formation, FoxA and Brachyury are later expressed in ectoderm and archenteron tip cells that will fuse to form the anal opening of the gut (Arenas-Mena, 2006, 2013), similar to the expression of the corresponding orthologs during the formation of the echinoderm and hemichordate mouth (Tagawa et al., 1998; Gross and McClay, 2001; Oliveri et al., 2006). This oral and anal conservation of gene expression suggests that FoxA and Brachyury are involved in the formation of both primary and secondary gut openings in protostomes and deuterostomes. The expression of FoxA orthologs similarly anticipates blastopore formation in Hydroides and yolky Capitella embryos (Boyle and Seaver, 2008) despite their very distinct gastrulation by invagination and epiboly, respectively. In contrast, the early and broad endodermal expression of Brachyury and Otx is absent from the epibolic embryos of Platynereis (Steinmetz et al., 2011; Arendt et al., 2001), indicating that passive internalization of endoderm

Fig. 3. Expression summary of Tbx2/3, FoxA 1, FoxA 2, Bra, Sall, Otx and T-Brain. Diagrams summarize relevant expression patterns described in the text. Expression is indicated in red; dashed lines and dashed fill indicate declining expression; in green, primary trochoblasts and prototroch for orientation. Arrows indicate morphogenetic events. All figures diagrammatic except for Otx and T-Brain, which are realistic surface renderings of fixed embryos. The expression summaries are not comprehensive. Detailed expression and additional stages are available for Tbx2/3 (Arenas-Mena, 2013), FoxA 1 and FoxA 2 (Arenas-Mena, 2006), Bra (Arenas-Mena, 2013), Sall (Arenas-Mena, 2013), Otx (Arenas-Mena and Wong, 2007), T-Brain (Arenas-Mena, 2008) and ciliary band gene expression (Arenas-Mena et al., 2007a). The cleavage pattern was characterized previously (ArenasMena, 2007b). a, anus; an, animal pole; at, apical tuft; bp, blastopore; cb, ciliary band; D, dorsal; fg, foregut; hg, hindgut; $L$, left; $m$, mouth; mg, midgut; 0 , oral; $R$, right; $v$, ventral.
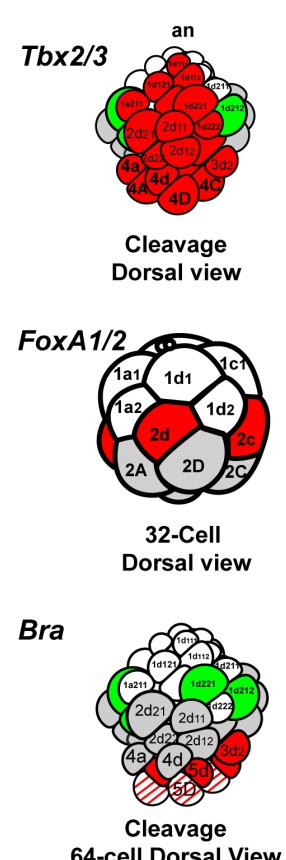

Sal

64-cell Dorsal View

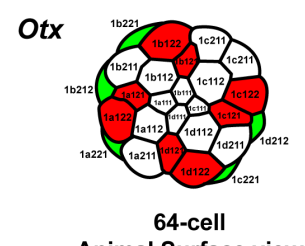

Animal Surface view

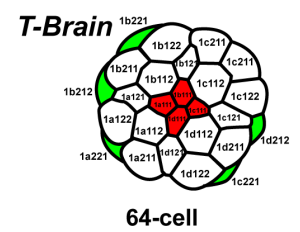

Animal Surface view by epibolic gastrulation does not require their expression. These gene expression similarities and differences between Hydroides direct development. Of course, more regulatory genes and polychaetes before substantial comparisons can be made.

Larval mesoderm precursors express Blimp, FoxA, Otx, Tbx2/3 Brachyuryand Sall(Arenas-Mena, 2006, 2008, 2013, Arenas-Mena and Wong, 2007). The fate of the expressing cells is difficult to ascertain, except in the case of Sall, which is expressed in terminal growth zone precursors (Fig. 3) and can be seen in some proto-
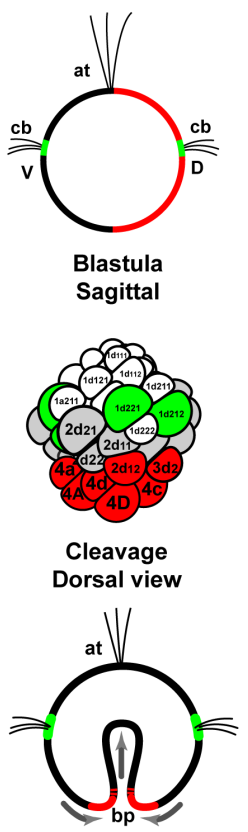

Gastrulation Frontal Section

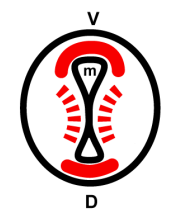

Vegetal

Surface view
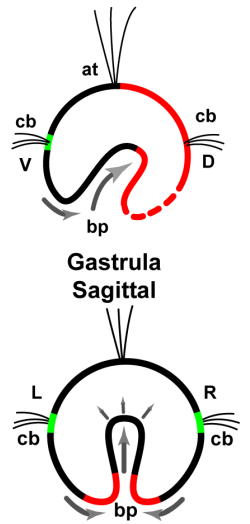

Gastrula Frontal section[

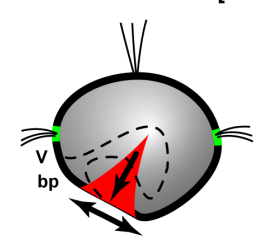

Convergent-extension (ectoderm surface view)

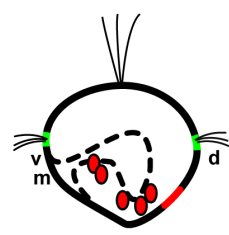

Sagittal Section

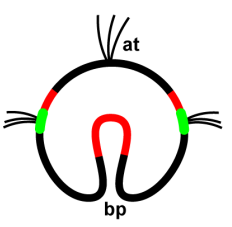

Gastrulation Frontal Section

Vegetal Surface view

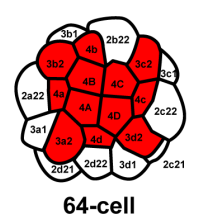

VegetalSurface view

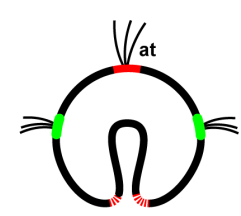

Gastrulation Frontal Section

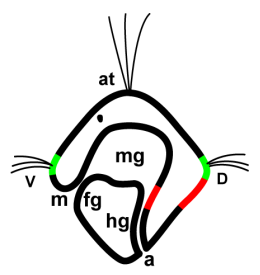

Trochophore larva Sagittal section
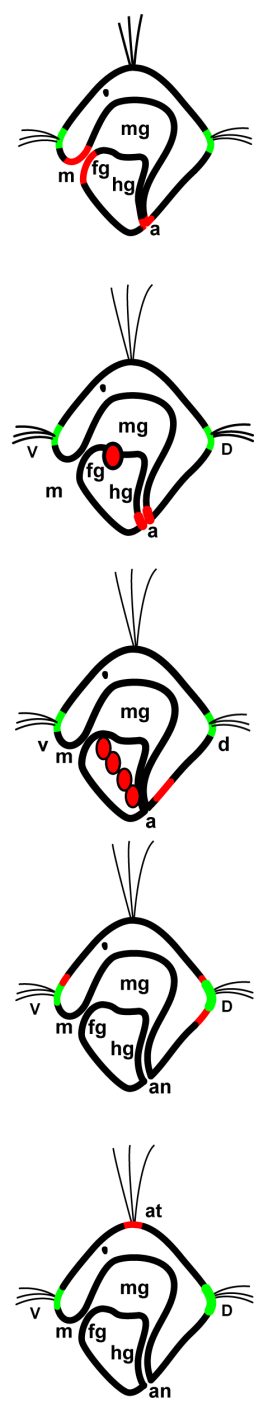

Trochophore larva Sagittal Section 
Fig. 4. Expression of trypsinogen mRNA during feeding stages. (A) Transversal plane of a 48-hour trochophore with two trypsinogen-expressing cells abutting the midgut. $(\mathbf{B} 1,2)$ Consecutive optical sections of a 72-hour larva with four trypsinogen-expressing cells. L, left; $R$, right; $m$, mouth; $m g$, midgut.
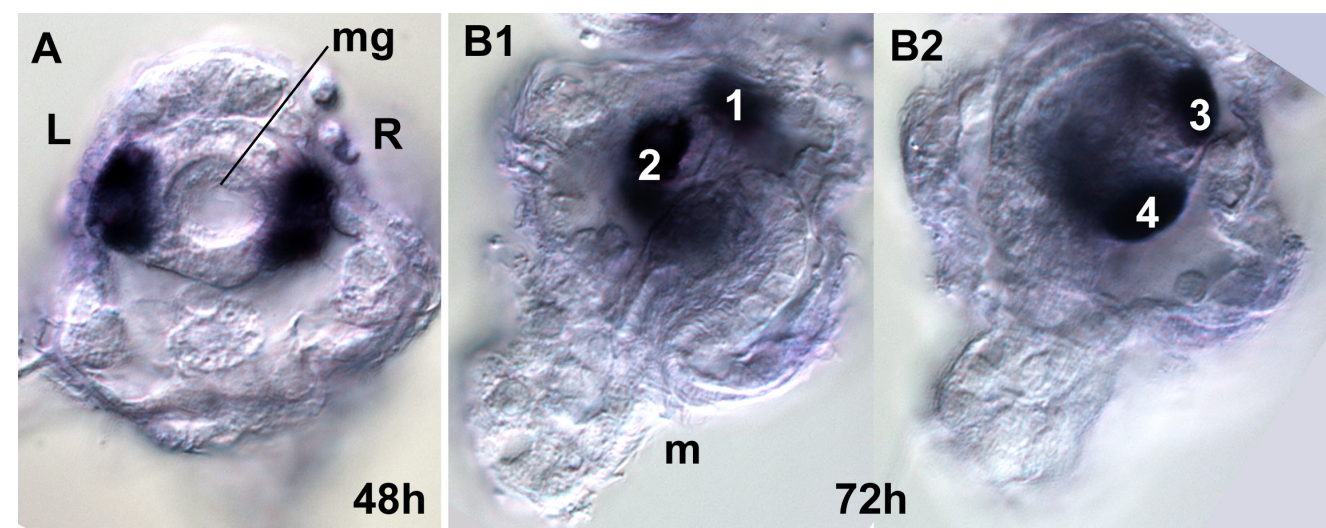

nephridium cells undergoing differentiation (Arenas-Mena, 2013).

In addition to their vegetal expression, several transcription factors are expressed in the animal cap. The apical tuft is a sensory organ at the animal tip of the trochophore marked by the expression of T-brain (Fig. 3) (Arenas-Mena, 2008). Blimp is expressed in animal-cap cells that could correspond to larval eye precursors (Arenas-Mena, 2008). Otx is expressed in ciliary band-associated cells that adopt a neural shape and also in cells associated with the putative posterior sensory organ (Nezlin and Voronezhskaya, 2003), just underneath the ciliary band gap (Fig. 3) (Arenas-Mena and Wong, 2007). We found evidence suggesting that animal cap cells squeeze through the dorsal ciliary band gap and migrate to the vegetal hemisphere (Arenas-Mena et al., 2007a), perhaps contributing to the dorsal sensory organ (Nezlin and Voronezhskaya, 2003), which has not been characterized in Hydroides but seems to be present based on the distinctive expression of Otx, $\beta$-thymosin and histone $H 2 A$. Z in five cells located just underneath the ciliary band gap (Arenas-Mena et al., 2007b, 2007a; ArenasMena and Wong 2007).

The trochophore is endowed with various ciliated cells with essential feeding, motor and sensory functions (Fig. 2). The expression of $\alpha$-tubulin, $\beta$-tubulin, tektin, caveolin and $\beta$-thymosin was characterized in Hydroides (Arenas-Mena et al., 2007a). The first larval cells to differentiate are the eight primary trochoblasts 1q221 and 1q212 (colored green in Fig. 2), which express $\alpha$-tubulin, $\beta$ tubulin, tektin and caveolin just after their formation and promptly contribute to the ciliated prototroch (Fig. 2). Caveolin is expressed in additional ciliated cells associated with the metatroch, gastrotroch, adoral ciliary zone, apical tuft, foregut and hindgut; $\alpha$-tubulin has a similar pattern of expression except it is absent in the foregut. Interestingly, the cis-regulatory elements driving the expression of $\alpha$-tubulin in the gastropod Patella vulgata are functional in various mollusks and the polychaete Platynereis dumerilii (Damen et al., 1997), suggesting that the upstream regulation of $\alpha$-tubulin could be homologous among spiralians.

\section{Postembryonic worm development}

The primary role of the feeding larva is to nourish its postembryonic development. The feeding trochophore of polychaetes is endowed with a prominent gut and minimal excretory and sensory organs (Fig. 2) (Hatschek, 1885; Shearer, 1911). If no phytoplankton are available, individuals at the larval stage can survive for months in the water column (Qian and Pechenik, 1998). With food provided,

inconspicuous $4 \mathrm{~d}$ and $2 \mathrm{~d} 22$ descendants will contribute to posterior growth and form the reproductive side of the animal (Fig. 2). After settlement in an appropriate substrate, a proteinaceous and, later, a calcareous tube will form (Carpizio-Ituarte and Hadfield, 1998). During the feeding-dependent developmental phase, some larval tissues undergo histolysis and some transform into adult tissues (Wisely, 1958; Segrove, 1941). Despite a rapid metamorphosis and settlement in just a few hours, the transition from larval to adult development is gradual, and does not clearly conform to the paradigm of "maximal indirect development" (see below).

In Hydroides elegans, larval growth is feeding-dependent, in contrast to polychaetes without feeding trochophores. This correlates with relatively small $4 \mathrm{~d}$ and $2 \mathrm{~d} 22$ in Hydroides and large $4 d$ and $2 d 22$ in more directly developing polychaetes (Fig. 2) (Anderson, 1966). The pattern of cell division during posterior growth and subsequent segmentation was characterized in Hydroides elegans and Capitella capitata, a polychaete with a non-feeding larva (Seaver et al., 2005). Posterior growth shows similarities between these two polychaetes during larval and postmetamorphic development, suggesting that formation of the segmented body is generally similar regardless of distinct embryogenesis. A peculiarity of Hydroides and other serpulids is the formation of thoracic segments by intercalation (Seaver et al., 2005; Segrove, 1941). In both Hydroides elegans and Capitella capitata, early posterior growth is characterized by lateral bands of dividing cells that apparently migrate to dorsal and ventral positions. Subsequent postmetamorphic growth is characterized in both polychaetes by elongation from classical posterior growth zones with semicircular arrangements in the left and right sides. Teloblastic growth from stem-like cells is absent in both polychaetes, suggesting that the teloblastic growth described in hirudineans represents a derived specialization (Seaver et al., 2005). Posterior growth zone precursors express the transcription factor Sall (Fig. 3) (Arenas-Mena, 2013), which is also expressed in the terminal growth zone of the crustacean Artemia franciscana where it controls Hox cluster gene expression (Copf et al., 2006). Hox cluster gene expression has not been characterized in Hydroides, but it is expected to be postembryonic and relegated in posterior growth zone descendants (Arenas-Mena, 2013).

\section{The expression of multipotency functions in Hydroides}

The proposed remodeling of the trochophore larva during adult transformation (Arenas-Mena 2010) would require some degree of 
multipotency in differentiated cells, which is counter to prevailing assumptions of development as a one-way process. Some larval organs such as the apical tuft and prototroch seem to be terminally differentiated and undergo histolysis and resorption during metamorphosis (Anderson, 1966). It also seems that differentiated cells, such as those of the stomodaeum and mid-gut, persist through metamorphosis and contribute to larval transformation (Anderson, 1966). However, these observations are generally superficial and no precise analysis of lineage, apoptosis/histolysis and differentiation during the larva-to-adult transformation has been performed. Natural transdifferentiation seems more common than previously thought and unambiguous cases have been reported (Richard et al., 2011; Wright et al., 2010; Sisakhtnezhad and Matin, 2012; Kagias et al., 2012). Evidence of transdifferentiation requires refined technique, and similar methods should be used to assert its absence. Transdifferentiation could prevail during the larva-to-adult transformation of Hydroides (Arenas-Mena, 2010; Anderson, 1966). In particular, the differentiated larva seems to undergo dramatic transformation that generates cerebral ganglia, the collar and the branchial crown (Segrove, 1941). These adult organs could derive from undifferentiated stem-cell precursors or differentiated larval cells (Arenas-Mena, 2010; Anderson, 1966). It seems that some larval cells expressing the trypsinogen differentiation marker proliferate during feeding stages, because the number of expressing cells is always even (Fig. 4), but it is unknown if larval cells are capable of switching their transcriptional profile to related differentiation states. Curiously, it does not seem that these cells have direct contact with the lumen of the gut, other than possibly through filopodia, and therefore it is uncertain how the digestive enzyme (trypsinogen) may be delivered into the gut.

We found that the expression of histone variant $H 2 A . Z$ correlates with transcriptional potency in indirectly developing sea urchins and Hydroides (Arenas-Mena et al., 2007b). Based on its association with regulatory DNA and its ability to prevent heterochromatin formation in yeast (Meneghini et al., 2003), one of us hypothesized that H2A.Z could have a transcriptional potency role by facilitating the accessibility of cis-regulatory sequences to transcription factors (Arenas-Mena, 2007a). Subsequent studies further support this hypothesis: H2A.Z associates with the regulatory DNA of promoters and enhancers across the genome, and H2A.Z is required to maintain transcriptional potency in stem cells (Hu et al., 2013). In Hydroides elegans embryos, H2A.Z transcripts decline first in the differentiating trochoblasts that stop dividing and form the ciliated prototroch, but expression remains in all other cells yet engaged in forming larval tissues and organs. In trochophore larvae, H2A.Z expression is maintained in descendants of mesodermal $4 \mathrm{~d}$ and ectodermal $2 \mathrm{~d} 2$, which are the potent precursors that will form the segmented reproductive side of the animal by posterior growth during the feeding-dependent phase. Similarly, expression declines during differentiation of the first three segments with chaeta-sacs, but it is maintained in the posterior growth zone that will generate the remaining segments (Arenas-Mena et al., 2007b). Interestingly, $H 2 A . Z$ seems to be reactivated in differentiated ectodermal cells of the trochophore larva that reengage in development and contribute to animal cap transformation (Arenas-Mena et al., 2007b). Therefore, H2A.Z is an excellent marker of potency, and its study will advance our understanding of the developmental transformation of larvae.

\section{Experimental advantages and challenges}

Attempts are underway to implement modern methods for the characterization of gene regulatory networks in Hydroides. Microinjection, electroporation and microbiolistic penetration are possible in Hydroides elegans, and these methods can be used to deliver DNA constructs, antisense morpholino oligonucleotides and SRNAi against regulatory genes (our unpublished results). Unfortunately, all three delivery methods cause considerable side effects in a substantial portion of embryos, which limits the interpretation of transient gene perturbation experiments. Promisingly, some embryos electroporated with FoxA sRNAi show gastrulation defects while all other developmental processes and organs appear normal, and this phenotype is not seen in control embryos (our unpublished results). The small eggs of Hydroides (Miles and Wayne, 2008) are difficult to microinject, and removal or softening of the fertilization membranes prevents normal development. Despite these difficulties, new methods have been developed that
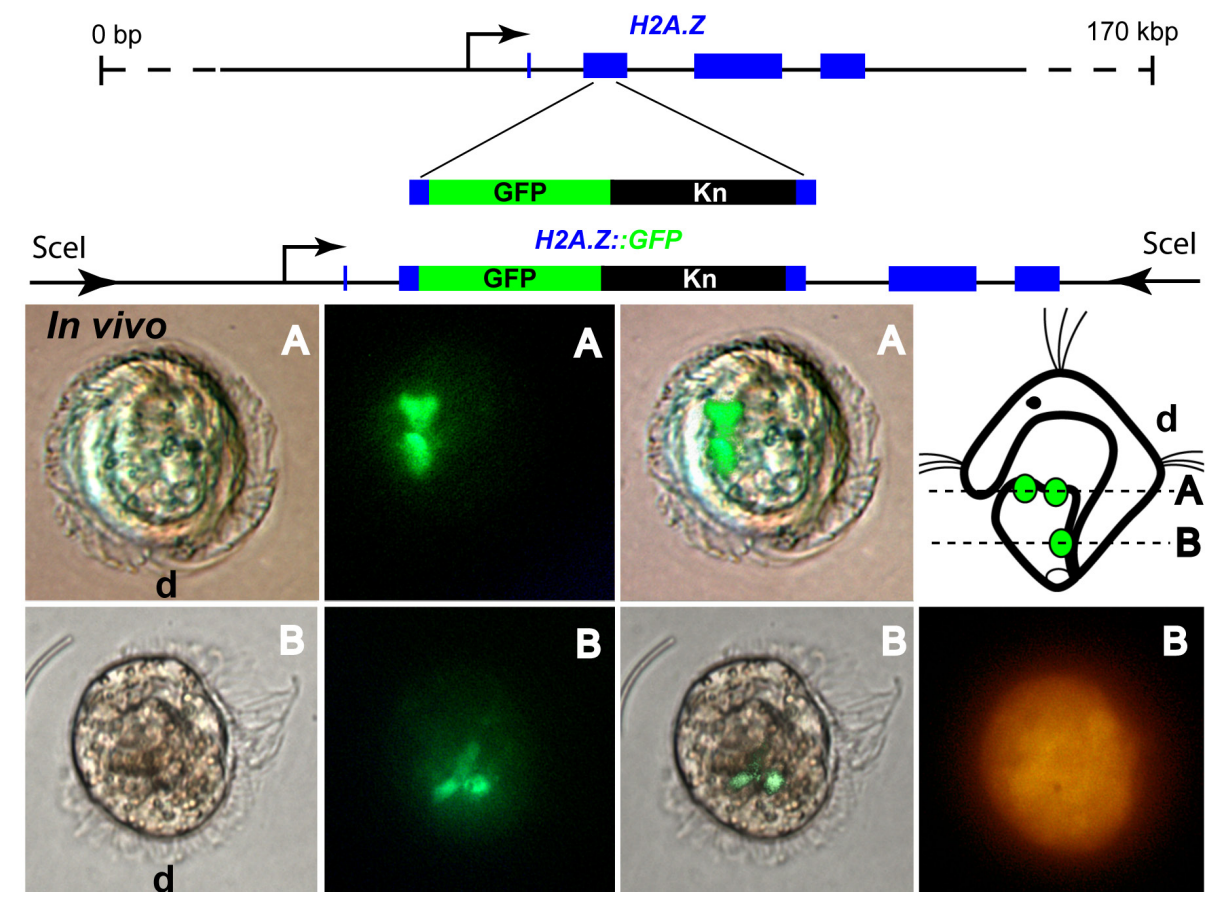

Fig. 5. H2AZ::GFP recombineering fusion reproduces $H 2 A . Z$ expression during embryogenesis. Diagram of H2A.Z::GFP translational fusion in a BAC clone used in microinjection. Bottom, almost immobilized living larvae at the one-eye stage. From left to right: bright field, fluorescent-GFP, and composite. Right bottom corner, red emission of co-delivered fluorescent dextran. Sectioning levels in top right diagram. Section A: GFP expression in putative protonephridium precursors flanking the gut. Section B: expression in multipotent $4 d$ posterior growth zone endomesoderm adult precursors. $d$, Dorsal. 
currently allow a portion of microinjected embryos to undergo normal development. We have generated a genomic BAC library, isolated a clone and generated a translational GFP::H2A.Z fusion that reproduces the endogenous expression pattern of $H 2 A . Z$ (Fig. 5). This is a promising result that will be followed by the consolidation of stable transgenic lines. Transgenic approaches will be facilitated in Hydroides thanks to its small size and short generation time (4 weeks in the laboratory) (Table 1).

Other biological features offer additional experimental advantages (Table 1). Genetic analysis should be facilitated by a genome distributed in 13 chromosomes (Vitturi et al., 1984), and sequencing of its $700 \mathrm{Mbp}$ genome is not particularly challenging. Substantial genetic polymorphisms are expected given the worldwide distribution of interconnected populations (Pettengill et al., 2007), and sampling during our cDNA cloning efforts is consistent with high sequence diversity. Protrandric hermaphroditism could in principle allow self-fertilization of eggs with frozen sperm from the male phase of the same individual, but, to our knowledge, this has never been attempted. Culture in the laboratory is facilitated by the small size of the adults, which can be nourished with algal cultures of Isochrysis galbana at room temperature in artificial seawater. Larvae can be reared with the same algal culture, and will metamorphose within one week. For the same reasons, Hydroides is a choice model for studies of larval settlement and metamorphosis (Shikuma et al., 2014; Carpizio-Ituarte and Hadfield, 1998; Qian and Pechenik, 1998; Hadfield et al., 2001; Huang et al., 2012). Regeneration of the operculum and body after transversal sectioning has been reported, including anterior body regeneration (Zeleny, 1902), which is less prevalent in polychaetes (Bely, 2006).

\section{Broader evolutionary relevance of polychaete feeding trochophores}

The feeding trochophore of Hydroides may derive from a larval stage present in the last common ancestor of bilaterians or it may represent a more recent adaptation (Jägersten, 1972; Peterson et al., 1997; Raff, 2008; Arenas-Mena, 2010; Fusco and Minelli, 2010). Phylogenetically diverse protostomes and deuterostomes have specialized planktotrophic larvae that undergo substantial adult transformation (Gilbert and Raunio, 1997; Pechenik, 2004), but we do not know if these ciliated larvae are homologous or represent convergent adaptations. In other words, we do not know if the last common ancestor of bilaterians was a direct or indirect developer. Although the dichotomy facilitates discourse, it does so at the expense of accuracy; in reality there are intermediate forms between absolute planktotrophic and lecithotrophic larvae (Allen and Pernet, 2007). Evolutionary scenarios have been proposed to explain the origin of indirect development, and compiled references can be found elsewhere (Page, 2009; Arenas-Mena, 2010; Sly et al., 2003). In short, terminal addition and its variants propose that macroscopic adults represent new stages that evolved as later addendums to the life cycle of an originally simple larva-like bilaterian (Peterson et al., 1997); in other words, complex adult stages represent the innovation. Intercalation models suggest that larvae evolved repeatedly during early developmental stages of complex bilaterians (Sly et al., 2003); in other words, larval stages represent the innovation. Both scenarios stress discontinuity between adult and larval development. In order to reconcile larval and adult development, both the terminal-addition (Peterson et al.,
1997) and intercalation (Sly et al., 2003) models invoke the evolution of multipotent "set-aside" cells (Pehrson and Cohen, 1986) in charge of adult development. Both models are inspired by extreme forms of "maximal indirect development" (Peterson et al., 1997), such as the development of adult tissues within the pilidium larva of some nemerteans (Maslakova, 2010) and the development of a pentameral adult within the bilateral larva of echinoids (ArenasMena et al., 2000; Maslakova et al., 2004; Page, 2009); in both cases, most larval tissues are resorbed and/or discarded during abrupt metamorphosis, and adult development derives primarily from "set-aside" precursor cells. Nevertheless, "maximal indirect development" is not representative among indirectly developing bilaterians. The adult body of extant echinoderms is certainly a derived condition; imaginal rudiments and abrupt metamorphosis resolve the incompatibility of the pentameral adult with the bilateral larval organization (Arenas-Mena, et al., 2000). Similarly, adult development from imaginal cells and dramatic metamorphosis represent an innovation in Pilidiophora nemerteans, with basal nemerteans undergoing a more gradual larva-to-adult transformation (Maslakova, 2010). Indeed, more common among indirect developers is a gradual transformation of the larva into the adult as previously discussed for indirectly developing annelids and mollusks (Page, 2009; Arenas-Mena, 2010). One of us has proposed that indirect development could evolve by gradual divergent adaptations in juveniles and adults (Arenas-Mena, 2010). This model proposes substantial developmental potential of differentiated cells allowing remodeling of larvae and juveniles during adult transformation (Arenas-Mena, 2010); we could dub this scenario as "juvenile/larva remodeling". Thus, in contrast with the intercalation and terminaladdition scenarios, there is no immediate need to evolve multipotent "set-aside" cells, although "set-aside" cells could evolve later as "developmental shortcuts" (Arenas-Mena, 2010). The origin(s) of the polychaete feeding trochophore remains an open question. Comparative gene expression among divergent developmental modes can be informative, as illustrated above, but comprehensive characterization of the gene regulatory scaffold for larval development seems necessary, as argued before (Arenas-Mena, 2010). Studies of developmental gene regulatory networks in Hydroides elegans should contribute to estimating the evolutionary dynamics

TABLE1

\section{INTERESTING PROPERTIES AND NUMBERS ABOUT HYDROIDES ELEGANS}

\begin{tabular}{lll}
\hline Chromosome number & 13 & (Vitturi et al., 1984) \\
Genome size & $700 \mathrm{Mbp}$ & T.R. Gregory Unpublished Data * \\
Generation time & $3-4$ weeks & (Hadfield, M.G. et al., 2001) \\
Feeding trochophore & 14 hours & (Arenas-Mena, 2007a) \\
Settlement & 5 days & (Carpizio-Ituarte, and Hadfield, 1998) \\
Egg size & $45 \mu \mathrm{m}$ & (Miles and Wayne, 2008) \\
Distribution & Subtropical worldwide & (Pettengill et al., 2007) \\
Gonochorism & Protandrous & (Miles and Wayne, 2008) \\
& hermaphrodite & \\
Cleavage & Equal-sinistral & (Arenas-Mena, 2007a) \\
D-quadrant asymmetry & 60 -cell embryo & (Arenas-Mena, 2007a) \\
Thorax diameter & About 1 mm & (R. Bastida-Zavala and H. Ten Hove, 2003) \\
Adult length & About 2 cm & (R. Bastida-Zavala and H. Ten Hove, 2003) \\
Left-right asymmetry & Operculum and eye & (Schochet, 1973; Hatschek, 1885) \\
Regeneration & Operculum and body & (Zeleny, 1902) \\
\hline *Animal Genome Size Database (http//www.genomesize.com/)
\end{tabular}

*Animal Genome Size Database (http://www.genomesize.com/) 
of developmental networks (Hinman and Davidson, 2007), and perhaps also to elucidating the origin (s) of indirect development.

\section{Acknowledgements}

Research in our laboratory has been supported by NIHNCRR grant 1R21RR024195 and several PSC-CUNY awards.

\section{References}

ALLEN J D and PERNET B (2007). Intermediate modes of larval development: bridging the gap between planktotrophy and lecithotrophy. Evol Dev 9: 643-653.

ANDERSON D T (1966). The comparative embryology of the Polychaeta. Acta Zool Stockh. 47: 1-42.

ARENAS-MENA C (2006). Embryonic expression of HeFoxA1 and HeFoxA2 in an indirectly developing polychaete. Dev Genes Evol. 216: 727-736.

ARENAS-MENA C (2007a). Developmental transcriptional-competence model for a histone variant and a unicellular origin scenario for transcriptional-multipotency mechanisms. Evol. Dev. 9: 208-211.

ARENAS-MENA C (2007b). Sinistral equal-size spiral cleavage of the indirectly developing polychaete Hydroides elegans. Dev. Dyn. 236: 1611-1622.

ARENAS-MENA C (2008). The transcription factors HeBlimp and HeT-brain of an indirectly developing polychaete suggest ancestral endodermal, gastrulation, and sensory cell-type specification roles. J Exp Zoolog. BMolDev Evol.310B:567-576.

ARENAS-MENA C (2010). Indirect development, transdifferentiation and the macroregulatory evolution of metazoans. Philos Trans $R$ Soc B Biol Sci. 365: 653-669.

ARENAS-MENAC (2013). Brachyury, Tbx2/3 and sall expression during embryogenesis of the indirectly developing polychaete Hydroides elegans. Int J Dev Bio/57: 73-83.

ARENAS-MENA C, CAMERON A R, DAVIDSON E H (2000). Spatial expression of Hox cluster genes in the ontogeny of a sea urchin. Development 127: 4631-4643.

ARENAS-MENA C and WONG K S-Y (2007). HeOtx expression in an indirectly developing polychaete correlates with gastrulation by invagination. Dev Genes Evol. 217: 373-384

ARENAS-MENA C, WONG K S-Y, ARANDI-FOROSANI N (2007a). Ciliary band gene expression patterns in the embryo and trochophore larva of an indirectly developing polychaete. Gene Expr Patterns 7: 544-549.

ARENAS-MENA C, WONG K S-Y, ARANDI-FOROSHANI N R (2007b). Histone H2A. $Z$ expression in two indirectly developing marine invertebrates correlates with undifferentiated and multipotent cells. Evol Dev. 9: 231-243.

ARENDT D, TECHNAU U, WITTBRODT J (2001). Evolution of the bilaterian larval foregut. Nature 409: 81-85.

BELY A E (2006). Distribution of segment regeneration ability in the Annelida. Integr. Comp Biol. 46: 508-518.

BASTIDA-ZAVALA R, TEN HOVE H (2003). Revlision of Hydroides gunnerus, 1768 (Polychaeta: Serpulidae) from the eastern Pacific region and Hawaii. Beaufortia Bull Zool Mus Univ Amst. 53: 67-110.

BOYLE M J, and SEAVER E C (2008). Developmental expression of foxA and gata genes during gut formation in the polychaete annelid, Capitella sp. I. Evol Dev. 10: 89-105.

CARPIZIO-ITUARTE E, HADFIELD M G (1998). Stimulation of metamorphosis in the polychaete Hydroides elegans Haswell (Serpulidae). Biol Bull 194: 14-24.

CHAN X Y, LAMBERT J D 2011. Patterning a spiralian embryo: A segregated RNA for a Tis 11 ortholog is required in the $3 a$ and $3 b$ cells of the llyanassa embryo. Dev Biol. 349: 102-112.

COPF T, RABET N, AVEROF M (2006). Knockdown of spalt function by RNAi causes de-repression of Hox genes and homeotic transformations in the crustacean Artemia franciscana. Dev Biol. 298: 87-94.

DAMEN W G M, KLERKX A H E M, and VAN LOON A E (1997). Cell-specific gene regulation in early molluscan development. Invertebr Reprod Dev. 31: 1-9.

FRITZENWANKER J H SAINA M, TECHNAU U (2004). Analysis of forkhead and snail expression reveals epithelial-mesenchymal transitions during embryonic and larval development of Nematostella vectensis. Dev Biol. 275: 389-402.

FUSCO G, MINELLI A (2010). Phenotypic plasticity in development and evolution: facts and concepts. Philos. Trans. R Soc B Biol Sci. 365: 547-556.

GILBERT S F, RAUNIO AM (1997). Embryology: constructing the organism. Sinauer
Associates, Sunderland, MA, USA.

GROSS J M (2003). LvTbx2/3: a T-box family transcription factor involved in formation of the oral/aboral axis of the sea urchin embryo. Development 130: 1989-1999.

GROSS J M, MCCLAY D R (2001). The Role of Brachyury (T) during Gastrulation Movements in the Sea Urchin Lytechinus variegatus. Dev Biol. 239: 132-147.

HADFIELD M G, CARPIZO-ITUARTE J E, DEL CARMEN K (2001). Metamorphic Competence, a Major Adaptive Convergence in Marine Invertebrate Larvae. Am Zool. 41: 1123-1131.

HATSCHEK B (1885). Entwicklung der trochophora von Eupomatus uncinatus. Arbt Zool Inst Wien vi: 121.

HINMAN V F, DAVIDSON E H 2007. Evolutionary plasticity of developmental gene regulatory network architecture. Proc Natl Acad Sci. 104: 19404-19409.

HUANG Y, CALLAHAN S, HADFIELD M G (2012). Recruitment in the sea: bacterial genes required for inducing larval settlement in a polychaete worm. Sci Rep. 2:228

JÄGERSTEN G (1972). Evolution of the metazoan life cycle: a comprehensive theory. Academic Press, London, UK.

KAGIAS K, AHIER A, FISCHER N, JARRIAULT S (2012). Members of the NODE (Nanog and Oct4-associated deacetylase) complex and SOX-2 promote the initiation of a natural cellular reprogramming event in vivo. Proc Natl Acad Sci. 109: 6596-6601.

LAMBERT J D (2010). Developmental Patterns in Spiralian Embryos. Curr Biol. 20:R72-R77.

LAMBERT J D, NAGY L M (2003). The MAPK cascade in equally cleaving spiralian embryos. Dev Biol. 263: 231-241.

MASLAKOVASA (2010). The Invention of the Pilidium Larva in an Otherwise Perfectly Good Spiralian Phylum Nemertea. Integr. Comp Biol. 50: 734-743.

MASLAKOVASA, MARTINDALE M Q, NORENBURG J L (2004). Vestigial prototroch in a basal nemertean, Carinoma tremaphoros (Nemertea; Palaeonemertea). Evol Dev. 6: 219-226.

MEAD A D (1897). The early development of marine annelids. J Morph 13: 229-326

MENEGHINI M D, WU M, MADHANI H D (2003). Conserved histone variant H2A $Z$ protects euchromatin from the ectopic spread of silent heterochromatin. Cell 112: 725-736.

MILES C M, and WAYNE M L (2008). Life history trade-offs and response to selection on egg size in the polychaete worm Hydroides elegans. Genetica 135: 289 -298.

NEZLIN L P, VORONEZHSKAYA E E (2003). Novel, posterior sensory organ in the trochophore larva of Phyllodoce maculata (Polychaeta). Proc. R. Soc. Lond $B$ Biol Sci. 270:S159-S162.

OLIVERI P, WALTON K D, DAVIDSON E H, MCCLAY D R (2006). Repression of mesodermal fate by foxa, a key endoderm regulator of the sea urchin embryo. Development 133: 4173-4181.

PAGE L R (2009). Molluscan larvae: pelagic juveniles or slowly metamorphosing larvae? Biol Bull. 216: 216-225.

PECHENIK J A (2004). Biology of the invertebrates. McGraw-Hill, New York, NY.

PEHRSON J R, COHEN L H (1986). The fate of the small micromeres in sea urchin development. Dev Biol. 113: 522-526.

PETERSON K J, CAMERON R A, and DAVIDSON E H (1997). Set-aside cells in maximal indirect development: Evolutionary and developmental significance. BioEssays 19: 623-631.

PETTENGILL J B, WENDT D E, SCHUG M D, HADFIELD M G (2007). Biofouling likely serves as a major mode of dispersal for the polychaete tubeworm Hydroides elegans as inferred from microsatellite loci. Biofouling 23: 161-169.

QIAN P-Y, PECHENIK J A (1998). Effects of larval starvation and delayed metamorphosis on juvenile survival and growth of the tube-dwelling polychaete Hydroides elegans (Haswell). J. Exp Mar Biol Ecol. 227: 169-185.

RAFF R A (2008). Origins of the other metazoan body plans: the evolution of larval forms. Philos Trans R Soc B Biol Sci. 363: 1473-1479.

RICHARD J P, ZURYN S, FISCHER N, PAVET V, VAUCAMPS N, and JARRIAULT S (2011). Direct in vivo cellular reprogramming involves transition through discrete, non-pluripotent steps. Development 138:1483-1492.

SCHILTHUIZEN M, DAVISON A (2005). The convoluted evolution of snail chirality. Naturwissenschaften 92: 504-515.

SCHOCHET J (1973). Opercular regulation in the polychaete Hydroides dianthus (Verrill, 1873). I. Opercular ontogeny, distribution and flux. Biol. Bull. 144: 400-420 
SCHOLZ C B, TECHNAU U (2003). The ancestral role of Brachyury: expression of NemBra1 in the basal cnidarian Nematostella vectensis (Anthozoa). Dev Genes Evol. 212: 563-570.

SEAVER E C, THAMM K, HILL S D (2005). Growth patterns during segmentation in the two polychaete annelids, Capitella sp. I and Hydroides elegans: comparisons at distinct life history stages. Evol Dev. 7: 312-326.

SEGROVE F (1941). The development of the Serpulid Pomatoceros triqueter. $Q J$ Microsc Sci. S 82: 467-540.

SHEARER C (1911). On the development and structure of the trochophore of Hydroides uncinatus (Eupomatus). Q J Microsc Sci. 56: 543-590.

SHIBAZAKI Y, SHIMIZU M, KURODA R (2004). Body Handedness Is Directed by Genetically Determined Cytoskeletal Dynamics in the Early Embryo. Curr Biol. 14: 1462-1467.

SHIKUMA N J, PILHOFER M, WEISS G L, HADFIELD M G, JENSEN G J, and NEWMAN D K (2014). Marine Tubeworm Metamorphosis Induced by Arrays of Bacterial Phage Tail-Like Structures. Science 343: 529-533.

SISAKHTNEZHADS, and MATINM M (2012). Transdifferentiation: a cell and molecular reprogramming process. Cell Tissue Res. 348: 379-396.
SLY B J, SNOKE M S, RAFF R A (2003). Who came first-larvae or adults? Origins of bilaterian metazoan larvae. Int J Dev Biol. 47: 623-632.

STEINMETZ P R H, KOSTYUCHENKO R P, FISCHER A, ARENDT D (2011). The segmental pattern of otx, gbx, and Hox genes in the annelid Platynereis dumerilii: The segmental pattern of otx, gbx, and Hox genes. Evol Dev. 13: 72-79.

TAGAWA K, HUMPHREYS T, SATOH N (1998). Novel pattern of Brachyury gene expression in hemichordate embryos. Mech Dev. 75: 139-143.

TREADWELL A L (1901). The cytogeny of Podarke obscura. J Morph 17: 399-486.

UTSUNO H, ASAMI T, VAN DOORENT J M, GITTENBERGERE 2011. Internal selection against the evolution of left-right reversal. Evol Int J Org Evol. 65: 2399-2411.

VITTURIR, MAIORCAA, CAROLLOT (1984). The chromosomes of Hydroides elagans (Haswell, 1883)(Annelida, Polychaeta). Caryologia 37: 105-113.

WISELY B (1958). The development and settling of a serpulid worm, Hydroides norvegica gunnerus (Polychaeta). Austral J Mar Freshw. Res 9: 351-361.

WRIGHT MA, MO W, NICOLSON T, RIBERAAB (2010). In vivo evidence for transdifferentiation of peripheral neurons. Development 137: 3047-3056.

ZELENYC (1902). Acase if compensatory regulation in the regeneration of Hydroides dyanthus. Arch Entwicklungsmechanik Org. 13: 597-609. 


\section{Further Related Reading, published previously in the Int. J. Dev. Biol.}

Brachyury, Tbx2/3 and sall expression during embryogenesis of the indirectly developing polychaete Hydroides elegans Cesar Arenas-Mena

Int. J. Dev. Biol. (2013) 57: 73-83

http://dx.doi.org/10.1387/ijdb.120056ca

Stable expression of Y-box protein 1 gene in early development of the abalone Haliotis diversicolor Jun Chen, Zhi-Sen Chen, Zi-Xia Huang, Cai-Huan Ke, Jie Zhang, Yi-Xiang Zhong, Wei-Wei You and Jing Zhao Int. J. Dev. Biol. (2012) 56: 369-375

http://dx.doi.org/10.1387/ijdb.113487zc

Planarian embryology in the era of comparative developmental biology José M. Martín-Durán, Francisco Monjo and Rafael Romero Int. J. Dev. Biol. (2012) 56: 39-48 http://dx.doi.org/10.1387/ijdb.113442jm

Evolutionary history of the Tricladida and the Platyhelminthes: an up-to-date phylogenetic and systematic account Marta Riutort, Marta Álvarez-Presas, Eva Lázaro, Eduard Solà and Jordi Paps Int. J. Dev. Biol. (2012) 56: 5-17 http://dx.doi.org/10.1387/ijdb.113441mr

Functional analysis of grimp, a novel gene required for mesodermal cell proliferation at an initial stage of regeneration in Enchytraeus japonensis (Enchytraeidae, Oligochaete)

Makoto Takeo, Chikako Yoshida-Noro and Shin Tochinai

Int. J. Dev. Biol. (2010) 54: 151-160

http://dx.doi.org/10.1387/ijdb.082790mt

Hox and ParaHox genes in Nemertodermatida, a basal bilaterian clade Eva Jiménez-Guri, Jordi Paps, Jordi García-Fernández and Emili Saló Int. J. Dev. Biol. (2006) 50: 675-679

http://dx.doi.org/10.1387/ijdb.062167ej

On the origin of pattern and form in early Metazoans

Frederick W. Cummings

Int. J. Dev. Biol. (2006) 50: 193-208

http://dx.doi.org/10.1387/ijdb.052058fc

Segmentation: mono- or polyphyletic?

Elaine C Seaver

Int. J. Dev. Biol. (2003) 47: 583-595

http://dx.doi.org/10.1387/ijdb.14756334

5 yr ISI Impact Factor $(2011)=2.959$

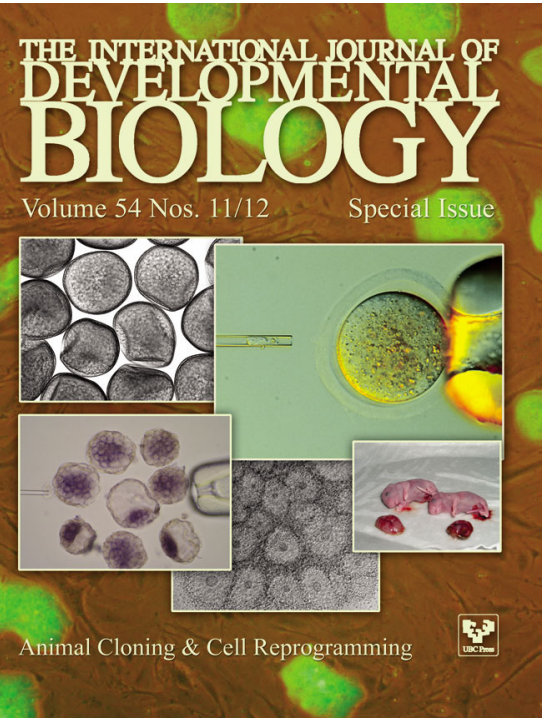

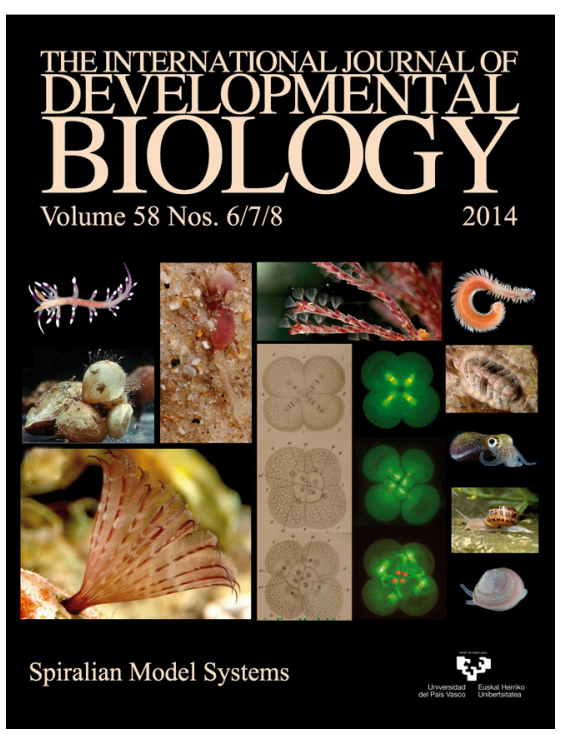
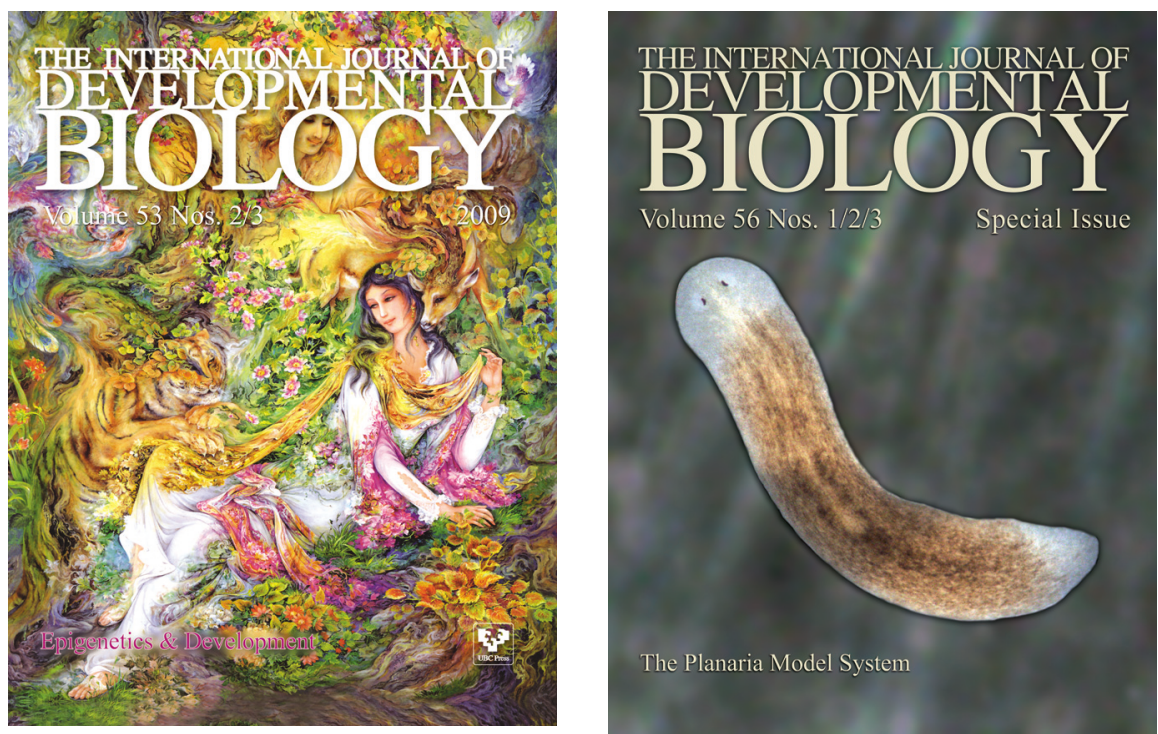